\section{POEMAS DE LOS LIBROS: ORILLAS DE TRÁNSITO Y LAS}

ESTACIONES AÉREAS

POEMS OF THE BOOKS: SHORES OF TRANSIT AND AIR STATIONS
De: Las Estaciones Aéreas, Ediciones Barba de Palo, Valdivia, 1999.

Segunda inmersión

Andre Racz en la memoria

"La memoria arroja y deja en seco

una multitud de cosas retorcidas;

una rama retorcida en la playa,

devorada; lisa y pulida

como si el mundo rindiera

el secreto de su esqueleto,

rígido y blanco".

T.S. Eliot

Llevarse de la vida solamente

algunos tesoros encontrados en la arena:

trozos flotantes, boyas de madera, brillantes colores

conchas, caracoles

los restos que sobreviven de un desastre náutico

los pequeños tesoros reunidos

cada verano

dispuestos a lo largo de la costa

para descifrar el paisaje.

Cada piedra tiene aquí su correspondencia

sus concavidades en mordisqueadas rocas

se coleccionan piezas, redes

en donde cada espacio vacío del rompecabezas

quema como la sal

quenas corcos de las manos de los pescadores.

eńlo rurcos de las manos de los pescado

pedazos dispersos de un libro benévolo

materia encontrada al azar para leer las señales el íntimo mapa de la existencia.

Terco otoñal

Terco el sol otoñal de mis días que me sueña y me duerme

Terco el quemador de testas, que entre plazas y parques

me obliga a recoger las hojas olvidadas y húmedas de su libro:

las metáforas que van a dar al resumidero del día

esas quebradas en donde musgo y paciencia

tejen la atmósfera de lo que es igual en el mundo.

Terco el que en su majadería pregona el "mi mano es muchas manos"

y la llamamos mi mano que escribe, boca y ojos cosidos

a m an oescribe

en este vasto cuerpo que somos

cuerpo en donde se congrega la tarde

con todo su sueño secular.

No es de la fosforescente rama de abedul

de donde cuelga la imagen

ni está en el resto de café en el fondo de la taza

ni en el humo de cigarro al final de la fiesta

ni tampoco en su sabroso olor entre mis dedos.

Apenas si se puede contener la tentación de escribir sobre una fotografía

magen desteñida de una memoria mecánic

cuando todo es imagen qué se puede decir 
mejor es amarrar la barca a la orilla de esta págin mientras las confusas instantáneas de la realidad den vueltas y vueltas como un disco en el pick-up

desprendiéndose de toda palabra innecesaria

toda metáfora de más:

y ya en la orilla, sólo el abedul

su fosforescente rama

para observar el cielo.

Cisneros habla a su hermano ambulante

Los libros son adobes de una torre que nunca edificaste

poeta ambulante,

y ofreces tus poemas en canastos al mejor oído postor.Ahuecas la cabeza para que

no te detenga

la sorna de tus hermanos

el duro asfalto de la tradición, la historia de la desmemoria.

Vistes la ingenuidad impenitente

en una gastada camisa limpia

para no contagiarte con la vergüenza ajena

soy poeta, escribo versos y cuento historias,

pero no escribo para usted

adivinas de soslayo el desprecio y la desconfianza

no hay corazón que te aguante

otro siembra el arbol, tiene el hijo y escribe el libro

porque eres de otro país, ambulante, de otro tiempo.

Porque naciste cuando el musgo envejecía entre los nuevos puentes sobre el río.

Notas para el reencuentro

El despunte de tu rostro en la ventana

(una quebrada de Valparaíso al fondo)

es un gesto de romanticismo

aqui en Valdivia o en cualquier parte.

El aire es uno solo entre las dos ciudades

y tu barba oxidada

el viento marino quizás

es la más bella poda de otoño a la que haya asistido.

Como tarde de domingo

entre café y los libros de siempre

un viento yue trae pastosos cane

ciones

(un viento literario, por cierto) lo desordena todo

La vieja memoria confunde

tus recuerdos y los míos, un poco de nostalgia

el cóctel perfecto.

La plaza es una fotografía

(la intervención de lo real)

el desembarco en la ciudad-puerto de los encuentros

mi hombre-muelle en quien llevar a cabo

la puesta en escena de esas metáforas

que imagino en mis viajes (imaginarios también)

algunas figuras de una retórica manoseada (como las bancas del muelle)

que ensayo en mis sueños hasta el cansancio

la ansiedad de atracar en ti

fondear, primero, tu desánimo

y allí

en el centro

otra vez

en la materialidad del abrazo

recrear

el lugar del poema.

primer andar

y así como el día y su transcurso nos enrolla como a un cigarro

porque al día hay que liarlo antes de fumárselo

y no se le puede guardar hecho

porque sabe distinto, seco

y no se puede tener días preparados, alineados en una caja

así como se suceden los temas en un disco

temas aprendidos de memoria y que podríamos tararear sin escucharlos

así presentimos los días y los adivinamos

y entre cada intervalo ensayar la entrada del piano, la trompeta o el saxo

así también se nos anuncia la mañana ya desde la taza de café

todo el día y sus intersticios en el calor de la humeante taza

su escritura escondida

que bebemos como a un muerto para hacerla nuestra.

Tercer y último andar

Pesado paso en el piso

condenado al surco que dibujas

sobre la tierra.

Es tu huella el inicio de otro viaje

ése del que tiene anhelo la pisada en el aliento

el intervalo

$\mathrm{Y}$ algunas hojas de tu libro se arrugan

otras se pierden en la penosa travesía.

No hay retorno en este bosque

Habrás perdido el mapa o ya no sabrás leerlo

El reverso de este viaje lo comienzas como a un viejo libro

ahora por detrás

leído al revés

es ya otra historia que te absorbe.

De: Orillas de Tránsito, Secretaría Regional Ministerial de Educación, Región de

Los Lagos. Colección de

Premios Luis Oyarzún, Santiago, 2003.

las secretas costumbres

"estoy convencido de que hay más rutina

en las aventuras que en un buen matrimonio". 
Cesare Pavese

todas las noches recorre mi espalda

escribiendo un poema que habla de nuestra historia:

el eterno regreso al matrimonio.

se comen frías lentejas mirándose a los ojos

encaramados

uno al otro como arañas a la pared

se interroga, se interpela, se grita

se mira el techo en la oscuridad y se adivinan los sueños

no estoy seguro de tu amor y otros boleros sisean en el aire

-prende la luz. -apágala.

-cuéntame algo.

Cuno conversamos la vida acabara pronto.

cuentame alguna historia, aunque sea la nuestra.

la vida está hecha de historias

miles de ellas como telas de araña.

téjeme cualquier cosa.

Entonces comenzaba:

"existimos para acompañarnos

alimentados de la ilusión

el pan del amor conyugal.

Retozar abrazados en el mismo jergó

cuando en verdad estamos separados por siglos de biografía,

siglos de identidad, siglos de soledad

en que cada uno duerme solo en la cuenca de sus ojos,

para reunirse en un sueño común

soñado al mismo tiempo

en el que compartimos casa, comida y lecho".

Pláticas

Nuestra conversación se vuelve

una sala de cine vaciándose lentamente

al terminar la película que nos deja inmóviles

mientras el acomodador nos mira ansioso

apurando la cháchara y el pasillo.

El espacio en blanco que media entre tu taza y la mia

(o entre un extremo y otro de la cama)

es un vacío, un silen

de esos que en las ciudades acumulan hiedra

basura

o crímenes.

en cajas de cartón

selladas y empolvadas bajo las camas

entre nuestras ropas y en el desván.

Como el amante que guarda los recuerdos de la amada

pinches caracoles marinos piedras cartas semillas

fotografías tristes testimonio

en una caja de zapatos como ataúd:

el rito del entierro es el mismo.
Tarareas una canción mientras lavas los platos

Lo interpreto como un gesto de romanticismo

una señal para deponer las armas.

Es la bruma de la muerte que viene hacia nosotros

la palabra no oída, la palabra gastada

flota inquietante sobre el puente.

El agua cayendo en susurros entre los trastos

no moja, no lava, no disuelve el silencio adherido

a todo el universo que poseemos:

un montón de ollas sucias.

Patios oscuros

breves tragaluces en que el sol apenas

alcanza en su oblicuidad

a entibiar la hiedra que sepulta

la fugaz niñez, recuerdo

allí

entre inusitado pasto y lápidas

jugamos a las bolitas o pedaleamos casi

una bicicleta que apenas se sostenía en pi

entre un extremo y otro del territorio.

Patios traseros

o laterales

una de las siete maravillas del mundo antiguo

cuyos jardines colgantes desafiábamos

con la mira de un juguete

ensayo precoz de las sucesivas muertes

que enfrentaríamos afuera

Patios breves

sombríos aleros de la casa de Dios,

la nuestra o la del vecino

tres cuartos de cemento y uno de prado

la mágica proporción del tedio.

Como en un ring

cada esquina es un aliento en donde crecen

pequeñas flores, heroicos brotes de resistencia vegetal.

Algo de terror habita en estos patios

la noche que sube en sus cañones, sube al sueño

las preguntas que cuelgan de sus jardines

tal vez el día entero pende de la verja

de pronto, el ladrido de los perros que nos ata al presente.

Sorprende el tránsito por esta zona oscura

en la que el sol ilumina a destellos

(igual que en mi memoria)

los rincones húmedos que habitan caracoles

musgos y chinitas.

Un muro lavado por la lluvia

ahuyenta a los intrusos.

El surco anaranjado que dibuja el zinc en el suelo

o mismo que afuera

luche o rayuela

seis, cinco 
descanso

cuatro, tres

descanso

dos y uno:

la cuenta regresiva

para entrar al cielo.

A Jorge

La provincia europea evapora su jornada

en gruesos telares de bruma,

telón de fondo para la prematura muerte del día.

Más allá,

la gran ciudad hierve entre copas y animadas charlas de mesón.

Somos unos viejos campesinos alemanes

bajando las persianas al frío y al mundo

que encienden sus lámparas de combustible

abrigan sus soledades

los poemas humean precoces a la noche.

¿Hacia dónde escapa la tarde de este hemisferio?

Lejos, al otro lado del mar, manos y pies taladrados

puedes contar todos tus huesos,

mientras nosotros, nos sorteamos tu túnica.

La heredad no es sólo materia, la casa de mi niñez y tus talismanes:

a cada uno toca también su porción de dolor,

su cuota de odio.

Me reservo, junto al hermano menor que ya no duerme

el beso de plata que sella tu muerte

os dos vástagos de tu maltratado tronco

unicos testigos y concelebrantes en esta temprana cena

eseso final, el adiós, la imagen religiosa bajo tu pech

soplo los ultimos secretos en tu oído hueco

el hijo desenreda la hiedra de tus dedos

que se graban en los míos

un padrenuestro ahogado

entre hipos

y mis disculpas por no llegar a tiempo.

Hacia donde escurre la tarde en tu hemisferio?

Los antiguos inmigrantes

traian consigo las herramientas para reproducir el pueblo natal.

En el viaje inverso me acompañan

os elementos del álbum familiar: el equeco de la historia.

La boda de los padres cuando caía el verano

para así no olvidar el origen

la ciudad azul, magnífica,

el día que enterramos el siglo

el nacimiento de nuestra hija

los amigos, las madres infinitas en su espera

la muerte presentida y tu expirar profundo

que me despierta a sobresaltos

a medio camino entre tu cama y un aeropuerto europeo.

¿Hacia dónde ascienden los sueños del hemisferio?

La foto reproduce una tarde feliz

el río entre niños y perros.

Una pobre orilla de playa a la que nos obligaba

el verano en la ciudad y su desierto.

La remota ninez se sumerge junto a las oxidadas formas de Valdivia entrevisto

entre pesados fierros y memoria.

La inmersion en aguas de lo antigu

cuando te creía nadador experto

de un río que oculta, aún hoy, el sonido de la muerte.

El incendio convoca a los curiosos en medio de la noche

como la llama de algún aniversario oficial

o zancudos al pabilo de la muerte.

La premonicion nos despierta de un mal sueño

para llevarnos a otro que transcurre a metros de la ventana.

La tarde anterior

entrevimos el caserón abandonado

entre el pasto y las lápidas del tiempo

y discutimos acerca del inexorable transcurso de la voz

sus campanadas perentorias

llamando al centro civico y sus rituales.

La noche atrozmente iluminada por la belleza de una hoguera

al lado, el río comunitario que nos ata al siglo y sus luces,

pasa como un ahogado pensativo, flotando

asido al lomo de la histor

La escena es atemporal

como pudo ser cien años atrás

quienes celebran, los mismos

en camisón y pantuflas, bruscamente iluminados

husmeando entre el carbón y las cenizas

buscando alguna pista, algun signo:

la truculenta forma de las llamas,

el trazado de las tablas en el suelo

los restos huneantes del desastre

para interpretar así, entre todos, el vaticinio. 